\title{
Kierkegaard: da "escolha \\ radical" ao estágio religioso
}

Kierkegaard: from "radical choise" to religious stage

DOI:10.12957/ek.2015.19868

Dr. Renato José de Moraes renatojmoraes@gmail.com

UFRJ

Em Enten-Eller (1842), Kierkegaard apresenta dois estilos de vida: o estético, que não se compromete por qualquer norma, e o ético. Segundo MacIntyre (1981), Kierkegaard propõe, como fundamento para a opção entre essas formas de vida, não argumentos racionais, incapazes de convencer, e sim a escolha radical da vontade. Com isso, o pensador dinamarquês representaria o final do projeto moderno de justificação racional das normas morais. São contrapostas a MacIntyre as opiniões de outros autores, que enxergam em Kierkegaard uma escolha justificada pela vida ética. Além do estágio ético, Kierkegard indica o estágio religioso, fundado na fé que tem em Abraão um modelo, que seria a mais alta possibilidade aberta para o ser humano.

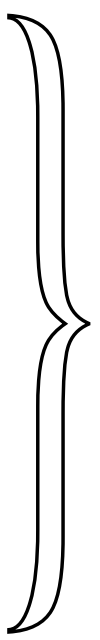

PALAVRAS-CHAVE Kierkegaard. MacIntyre. Ética moderna. Fé. Estágios de vida

In Enten-Eller (1842), Kierkegaard describes two life-styles: the aesthetical, which is not bound by any norm, and the ethical. According to MacIntyre (1981), Kierkegaard did not propose, to ground the option between these ways of life, rational arguments, unable to convince, but a radical choice of the will. The Danish thinker represents the end of the modern project of rational justification of the moral norms. Some authors criticized MacIntyre's views, and they defend that Kierkegaard proposes a justified choice for the ethical life. Beyond the ethical stage, Kierkegaard proposes the religious stage, founded on the faith whose model is Abraham, which would be the highest possibility open to the human being.

KEYWORDS Kierkegaard. MacIntyre. Modern Ethics. Faith. Life stages 


\section{A. A posição de Enten-Eller na filosofia moral}

Em seu influente livro After virtue (1981, $1^{\text {a }}$ ed.), Alasdair MacIntyre sustenta que Enten-Eller, de Kierkegaard, escrito em 1842, representa a primeira vez em que um ponto de vista específico sobre a ética aparece de forma plenamente desenvolvida. Tal ponto de vista se caracterizaria por considerar o debate moral em termos de confrontação entre premissas morais incompatíveis e incomensuráveis entre si, sendo a adesão moral nada mais que a expressão de uma escolha sem critério entre tais premissas; ou seja, um tipo de escolha que não pode ser fundada em uma justificação racional (MACINTYRE, 2007, p. 39).

Sendo assim, trata-se de um momento fulcral do desenvolvimento do pensamento moral na história do Ocidente, a partir do qual encontraremos características que teriam se tornado cada vez mais nítidas em nossas sociedades. Tais características terminariam desembocando na dificuldade enorme, que sentimos nos dias de hoje, para obter o consenso a respeito de aspecto morais centrais, consenso esse necessário para permitir que a vida em sociedade possa se desenvolver de maneira pacífica e harmônica.

As diferenças entre os pontos de vista a respeito da bondade ou maldade de certos atos e comportamentos humanos, sem que possa haver um arcabouço razoável para determinar a melhor solução, traz tensões graves para o mundo político. A vitória na discussão - se é que se pode chamar de discussão - é devida à força física, à habilidade política e à manipulação, e não ao mérito ou correção dos argumentos apresentados.

Para MacIntyre, Enten-Eller é o resultado e o epitáfio da tentativa sistemática, realizada pelo Iluminismo, de descobrir uma justificação racional para a moralidade (MACINTYRE, 2007, p. 39). Essa justificação racional, caso houvesse sido bem sucedida, impediria que chegássemos à incomensurabilidade entre posturas morais que encontramos hoje. Portanto, é evidente que o referido projeto falhou. Porém, muito antes que sentíssemos esses efeitos de um modo que podemos denominar sociológico, a obra de Kierkegaard teria já mostrado que esse projeto era inviável. Ademais, o pensador dinamarquês proporia uma saída diferente, que visava explicar a opção por uma postura moral em detrimento de outra: seria uma escolha da vontade sem um motivo prévio.

De acordo com esse entendimento sobre Kierkegaard, este passaria a ser o primeiro voluntarista ético absolutamente consequente. Ao contrário de seus predecessores, abandonaria as tentativas canhestras de sustentar que a moralidade teria seu fundamento no interesse, na razão, nos bons sentimentos, no 
prazer, e em outros conceitos ou realidades insuficientes para providenciar uma teoria ética coerente e desenvolvida.

\section{B. O uso dos pseudônimos por Kierkegaard}

Sendo Enten-Eller um livro tão importante historicamente, por representar uma ruptura e um novo direcionamento, convém examiná-lo detidamente. De acordo com MacIntyre, há três aspectos que devemos ter em conta a respeito dessa obra. Em primeiro lugar, a própria forma escolhida por Kierkegaard para expor seu pensamento no livro. Tal forma traria em si uma mensagem importante, porque indicaria a aporia que o autor desejava mostrar, que é a da impossibilidade de se decidir, de forma neutra e meramente racional, por uma concepção específica de moralidade.

Nesse sentido, Enten-Eller é constituído de escritos de dois pseudônimos - melhor diríamos heterônimos, no sentido em que foram utilizados por Fernando Pessoa -: "A", que expõe o modo de vida estético, e "B", que defende a vida ética (EVANS, 2004, p. 37-9). Tais escritos de " $A$ " $\mathrm{e}$ " $B$ " teriam sido editados por um novo heterônimo, Victor Eremita. Kierkegaard, ele mesmo, não se decide expressamente por nenhuma das possibilidades plasmadas em seus personagens / escritores ${ }^{1}$. Antes, criou ambas figuras, que defenderiam uma visão e não se entenderiam de maneira racional, porque os argumentos racionais sriam impossíveis para um convencer o outro, conforme veremos mais adiante.

Sempre segundo MacIntyre, a escolha entre o ético e o estético não é uma escolha entre o bem e o mal; antes, é uma escolha anterior, a respeito de se devemos ou não escolher em termos de bem ou mal. Ou seja, se cabe dirigir a vida a partir de princípios de certo ou errado, de moral ou imoral - o que corresponderia à esfera ética -, pois o ponto de vista do estágio estético pressupõe a perda do próprio eu no imediatismo da experiência presente (MACINTYRE, 2007, p. 40). Logo, o próprio uso da razão, para determinar uma opção, seria impossibilitado pelo caráter da vida estética; por isso, o ético não teria como oferecer argumentos para demover o adversário. Este sempre teria como se proteger e manter sua escolha inicial.

1 Ao contrário de MacIntyre, EVANS, 2004, p. 56-7, sustenta que Kierkegaard termina por se mostrar do lado de "B", o Juiz Guilherme, pois é evidente que o modo de vida adotado por "A" leva à ruína e à destruição. 
De fato, optar entre o caminho estético ou o ético exige escolher antes de tudo quais os primeiros princípios pelos quais o agente ou sujeito se guiará. Como se tratam de primeiros princípios, não há razões anteriores que justifiquem a adesão a eles. Pelo contrário, a partir deles é que as demais opções serão desenvolvidas. Eles tornam coerente - de certa maneira - a postura ética ou a estética, sem que eles mesmos possam ser considerados coerentes ou fundamentado. Não se trata, portanto, de uma eleição fundada em motivos justificáveis de forma racional, mas uma opção em certo sentido pura, prévia a qualquer outra adesão.

Essa noção de uma escolha vazia, prévia a qualquer justificação ou motivo, que por isso mesmo garantiria a liberdade do agente, será mais estudada em outro item. Mas podemos adiantar que se trata de uma visão bastante difundida a respeito do que seja a liberdade humana, de modo especial entre filósofos existencialistas e de algum modo tributários do nominalismo medieval.

Portanto, quando alguém já escolheu que será levado pelo cumprimento do dever ou pelo aperfeiçoamento moral, isso significa que escolheu que os argumentos dessa posição têm força para ele. Além disso, indica que tal escolha não foi precedida por qualquer razão ou motivo intelectual. Antes, como dissemos, serviria de fundamento para as posteriores escolhas racionais, que seriam realizadas dentro da concepção geral à qual se aderiu previamente. Apenas depois da escolha radical caberia falar de escolhas racionais, de modo especial na esfera ética, pois a esfera estética, em certo sentido, nega que a razão supere a sensação do instante e o poder da imaginação e possa servir de base para as opções do sujeito.

$\mathrm{Na}$ óptica de MacIntyre, Kierkegaard se equivocaria ao sugerir - de maneira sutil e indireta pela pena de "B" - que qualquer pessoa, que enfrente seriamente a escolha entre a vida ética e a estética, de fato optará pela primeira, pois a energia, a paixão, da escolha séria conduzirá o indivíduo ao caminho ético (KIERKEGAARD, 2009b, p. 31-3). Para MacIntyre, o estético também poderia ser escolhido séria e consequentemente, mesmo que o agente fosse carregado pelas suas paixões (2007, p. 41).

Neste ponto, surge algo bastante curioso. MacIntyre, ao defender a possibilidade de uma escolha consciente do modo de vida estético, apresenta como exemplo a geração britânica que foi à Primeira Guerra Mundial. Após ter presenciado os massacres em Ypres e Somme, vários desses jovens retornaram com a determinação de que nada mais iria importar-lhes, e por isso inventaram a trivialidade estética dos anos de 1920. Ora, para justificar a adesão desses jovens ao estado estético, MacIntyre mostra que eles possuíam - ou pelo menos acreditavam que possuíam - motivos para escolher a indiferença moral (2007, p. 41). 
Logo, não é uma "escolha radical", compreendida como não fundamentada, mas algo consequente com uma experiência vital e a maneira como se reagiu a ela.

Nesse sentido do exemplo apresentado pelo filósofo escocês, a postura estética não seria então irracional; sua escolha pelo efêmero e pelas sensações seria, em si mesma, tão racional quanto a escolha pela esfera ética. Em princípio, parece-me que Kierkegaard não aderiria a essa interpretação, porque penso que ele concordaria, nesse ponto, com "B" a respeito de que a escolha séria levará ao plano ético.

MacIntyre reconhece que seu entendimento da relação de Kierkegaard com Enten-Eller diverge substancialmente da que o próprio filósofo dinamarquês explicita posteriormente, quando ele comenta seus próprios escritos. Nessa ocasião, Kierkegaard sustenta que sua obra deve ser entendida como fruto de uma vocação única que não mudou. Também discordam de MacIntyre outros especialistas na filosofia e vida de Kierkegaard, que não enxergam a existência dessa decisão radical em relação à opção ética e à estética. Porém, MacIntyre insiste em que, em vista do que sabemos da biografia do pensador estudado, este se mantinha numa relação ambígua com sua nova ideia de uma fundamentação não-racional para a escolha vital primeira e primordial do agente $(2007$, p. 41).

\section{Os fundamentos dos princípios morais em Enten-Eller}

O segundo aspecto relevante de Enten-Eller seria a incoerência nuclear do seu argumento. $\mathrm{O}$ modo de vida ético seria aquele cujos princípios independem da opinião ou capricho de quem adere a eles. Descartar os princípios quando eles se tornam incômodos ou árduos indicaria que, mais do que desrespeitá-los, nós nunca aderimos a eles efetivamente. A força dos princípios advém das razões pelas quais os adotamos, que podem ser, por exemplo, religiosas, para a saúde, ou pela convivência com os demais. No entanto, Kierkegaard propõe que os princípios éticos são escolhidos sem que uma razão mostre que eles são os mais apropriados. Em outras palavras, a escolha é que deveria servir como razão para adoção dos princípios.

Teríamos aqui, novamente segundo MacIntyre, uma contradição clara. Afinal, admitiríamos que o ético tenha autoridade sobre nós; porém, como algo que aceitamos sem nenhuma razão poderia de fato ter autoridade sobre nós? (MACINTYRE, 2007, p. 41-3). A pura vontade imotivada, assim, não representaria 
algo firme o suficiente para garantir que o indivíduo seguisse coerentemente o caminho ético, pelo simples fato de têlo escolhido antes. Antes, a escolha apenas se manterá sólida se apoiada em razões convincentes, que é exatamente o que Kierkegaard, conforme a interpretação de MacIntyre, não admite em 1842.

Nesse ponto, Kierkegaard seguiria uma característica moderna, que é a separação entre a razão e a autoridade; mais ainda, a contraposição de uma à outra, de modo que recorreríamos à autoridade quando não tivéssemos razão para optar por um lado ou outro (MACINTYRE, 2007, p. 42). O que também não deixa de ser ambíguo, porque apenas recorreríamos a uma autoridade se tivéssemos um motivo para fazê-lo, e tal motivo deveria estar relacionado com a razão. Essa contraposição tem algo de absurdo, mas parece se encaixar bem na visão que MacIntyre apresenta sobre a ruptura que se encontraria no livro de Kierkegaard, com a recusa de razões primeiras para justificar as opções morais fundamentais.

Por fim, a terceira característica importante de Enten-Eller seria a feição conservadora e tradicional de Kierkegaard a respeito da ética. Nos dias de hoje, a noção de escolha radical vem junto ao questionamento sobre quais princípios éticos devemos escolher. Assim é porque estamos conscientes de que há morais alternativas e rivais diante de nós; com isso, além de se decidir entre levar ou não uma vida ética, seria preciso a seguir determinar qual caminho ético conviria abraçar, pois há vários deles disponíveis.

Kierkegaard, porém, combina a escolha radical com uma concepção específica da ética, não aberta a possibilidades distintas. O que não fosse estético seria necessariamente ético; em consequência, o homem ético não teria grandes problemas de interpretação. Uma vez que ele tivesse escolhido viver levando a sério a lei moral, ele consequentemente aderiria à moral então vigente na grande parte dos países europeus. Ou seja, caso alguém quisesse viver conforme as normas morais, não teria qualquer dificuldade em identificar quais elas seriam, por não haver moralidades concorrentes.

Essa característica significa que o autor forneceu uma nova base prática e filosófica - com fundamento na escolha voluntária sem justificação - para um modo de vida, para um conjunto de comportamentos e para normas morais mais antigos e herdados de gerações anteriores desde séculos. Para MacIntyre, talvez seja exatamente essa combinação entre novidade e tradição que gera a incoerência que se encontra no coração da posição de Kierkegaard (MACINTYRE, 2007, p. 43): uma justificação voluntarista, e nesse aspecto revolucionária e inédita, que termina por fundamentar regras vividas desde muito tempo, ainda que frequentemente de forma hipócrita, pela "cristandade" tão criticada pelo escritor dinamarquês. 
Chegamos aqui a um aspecto central da visão de MacIntyre a respeito da história do pensamento moral, mais em concreto daquele gerado pelo Iluminismo. Os vários autores posteriores a Descartes - incluindo figuras tão distintas entre si como Hume, Bentham, Kant e Diderot - teriam fracassado ao buscar uma fundamentação para as normas morais tradicionais, quer dizer, das que eram vigentes em suas sociedades. O motivo desse fracasso seria o esquecimento de que a natureza humana tende a uma plenitude, e que a função das regras morais é exatamente levar a que o ser humano passe do seu estado natural atual, cheio de falhas e lacunas, para aquele em que ele se encontre perfeitamente desenvolvido enquanto ser humano. Sem que se saiba a finalidade das normas - o aperfeiçoamento do indivíduo tendo em vista a sua natureza dinâmica, a partir de uma concepção da natureza como princípio de operações e de adaptação -, essas se tornam vazias ou suspensas (MACINTYRE, 2007, p. 36-61). De fato, se não se sabe para onde se quer chegar, torna-se difícil até mesmo entender as orientações sobre o caminho a ser tomado.

Então, toda a construção de Kierkegaard, considerada dentro do movimento espiritual em que ele está inserido, que é o dos estertores do Iluminismo, consistiria numa procura de fundamentar as normas éticas, pelas quais ele e a sua sociedade se guiavam, num ato da vontade. Essa empreitada foi levada adiante porque as tentativas anteriores haviam se mostrado equivocadas e, em maior ou menor medida, foram demolidas. Kant, por exemplo, tentara encontrar essa fundamentação, procurando normas racionais e universais que servissem como diretivos para o comportamento (MACINTYRE, 2007, p. 45); Hume o fez propondo as paixões como elemento sustentador da vida moral; Bentham, por sua vez, buscou na utilidade a motivação do agir moral, e vários outros autores apresentaram diferentes soluções, todas descartadas mais cedo ou mais tarde.

A relação entre Kant e Kierkegaard é especialmente importante, porque o primeiro, ao não conseguir seu objetivo de demonstrar que a razão prática, sozinha, seria capaz de justificar as normas morais universais e obrigatórias, abre o caminho para que o segundo busque a via da vontade como fonte da obrigatoriedade das normas morais. Portanto, Kant forneceu a Kierkegaard o ponto de partida (MACINTYRE, 2007, p. 47), exatamente porque a tentativa do primeiro havia se mostrado infrutífera.

Terence Irwin, professor de ética da Universidade de Oxford, reconhece a dependência de Kierkegaard em relação a Kant. Apesar de ser em muitos aspectos singular e idiossincrático, o pensador dinamarquês é em grande medida um homem do seu tempo, e então - como em muitos aspectos continua a ser 
hoje em dia - era impossível afastar-se totalmente da filosofia kantiana. Em concreto, podemos verificar que, se o homem estético afasta-se das normas e do comprometimento pessoal, a fim de se deixar guiar pela satisfação trazida pelo instante, o homem ético precisa da razão - que podemos compreender em sentido em parte kantiano - para determinar as normas que seguirá, isto é, quais são preferíveis a outras (IRWIN, 2009, p. 308). A razão não servirá para fundamentar a "escolha radical" entre via estética e ética; porém, uma vez decidida essa opção, a razão passará a agir, principalmente se a escolha recair sobre a via ética.

Essas considerações simples reforçam que Kierkegaard é um pensador de fato ancorado no pensamento ético da modernidade. Ainda que aceitemos a tese de MacIntyre, de que o escritor dinamarquês demonstrou que o projeto iluminista de justificação racional das regras morais era inviável, somos levados a reconhecer que Kierkegaard pensa e escreve - ao menos em grande parte - na atmosfera da modernidade. Porém, seu espírito não é propriamente moderno, como demonstra a solução religiosa que ele propõe para o problema moral do indivíduo. Tal solução, comparada com as oferecidas pelos seus contemporâneos, seria anacrônica. O que não tira, mas antes aumenta a força e radicalidade dela. Tal solução, porém, não havia ainda sido apresentada na altura em que ele escreveu Enten-Eller; porém, estará bastante delineada em um escrito imediatamente posterior, Temor e tremor.

\section{Os fundamentos da escolha}

O entendimento de MacIntyre a respeito da escolha radical, que para Kierkegaard serviria de fundamento para a adoção da vida ética ou da vida estética, sem argumentos racionais nos quais ela se estribasse, foi bastante criticado por uma série de autores.

A noção de que uma escolha primeira deva ser feita sem motivos que a justifiquem, porque, ao apresentar razões, a escolha fundamental de aceitar ou não a vida moral já terá sido feita, optando, consequentemente, pela existência ética ou pela estética, é algo confusa. Na realidade, qualquer escolha é sempre precedida por razões, que são ponderadas e levam a preferir um caminho a outros. Sem as razões, não caberia falar propriamente de escolha, mas de mera arbitrariedade ou fatalidade. Esse é um ponto fundamental da teoria da ação aristotélica, e convém compreendê-lo. 
Para alguns pensadores, sujeitar qualquer opção a razões levaria a diminuir a liberdade. Esta se ergueria com perfeição quando viesse unicamente da vontade do agente, que a escolhe sem ser guiado por qualquer consideração ou razão anterior. Esta concepção de liberdade pura, que podemos chamar de liberdade de indiferença, é típica da modernidade e tem suas raízes no pensamento de Duns Scot e Guilherme de Ockham (ADAMS, 2006, p. 245), frades franciscanos que escreveram suas obras no final do século XIII e começo do XIV. Neste ponto de vista, a vontade se sobrepõe à razão, porque ela é capaz de inclusive ordenar a razão a exercer seus atos próprios.

Ademais, a vontade manteria sempre sua indeterminação diante de quaisquer motivos que lhe fossem dados para decidir de um modo ou de outro. A liberdade consistira primordialmente nesta indefinição frente ao que fosse, que não a própria inclinação da vontade. Se a liberdade estivesse, de qualquer forma, dependente de algo diferente dela mesma, então não seria perfeita, mas condicionada. Consequentemente, cada vez que é exercitada, a vontade o faz ex novo, sem nada que a direcione para cá ou para lá. Por isso, todo ato humano deve ser compreendido em sua singularidade, porque a liberdade pode decidir de maneiras diferentes em cada ocasião. Nota-se que esta é uma postura pura, intensa e forte.

Por outro lado, na concepção aristotélica, o agente age sempre buscando um bem. Isso não pode ser mudado, é uma espécie de determinação característica da nossa humanidade. Pode suceder que o sujeito se equivoque sobre o que represente efetivamente o melhor para ele em determinada situação, seja considerando-a de maneira abstrata - por exemplo, é melhor passar a tarde em um bar do que ir ao trabalho na maior parte das vezes -, seja de maneira prática - neste instante, prefiro ir ao trabalho do que ao bar -, mas não é isso o importante. Seja como for, toda decisão apresentará uma motivação, algum bem que é buscado com a ação deliberada e decidida. Tal motivação poderá, em princípio, ser descoberta pelo agente, ao examinar seus próprios motivos; nem sempre por terceiros. Essa concepção é chamada por Servais Pinckaers, um importante teólogo belga, de liberdade de qualidade, em contraposição à liberdade de indiferença (PINCKAERS, 2007).

Então, como poderíamos explicar que alguém possa preferir não realizar um ato, que a razão mostrou-lhe como o melhor, em favor de outro, que ele tem consciência de que o prejudicará? Apesar de intelectualistas estritos julgarem que, por trás de uma ação moralmente equivocada, sempre há um desconhecimento, ou seja, uma falha da inteligência na compreensão do que é o bem, a posição de Aristóteles é que o homem pode escolher de maneira diferente do que a razão lhe apresente como o melhor. 
O motivo disso é que, ao decidir, o ser humano não se nutre apenas de motivos intelectuais. Quem ele é, seu caráter, influencia tremendamente as suas escolhas. Para o intemperante, não há nada melhor do que seguir as suas concupiscências (ARISTOTLE, 1991, p. 39). Ele pode até considerar, de maneira geral, que seria melhor deixar de beber para cuidar dos filhos; porém, no momento em que tem diante de si a bebida ou um prazer, este lhe parece um bem maior do que qualquer outro, e por isso decide em seu favor. Não se trata de que ele não seguiu aquilo que sabia ser o bem; o que ocorre é que na prática, no caso concreto, onde a ação moral é exercida, ele viu o bem naquilo que satisfaz a sua intemperança, e não na sua responsabilidade para com terceiros. Pode posteriormente arrepender-se, querer modificar sua conduta, mas seria falso sustentar que, no momento da ação, não tenha querido realizá-la (ABBÀ, 1995, p. 278).

A liberdade segue defendida nesta visão do ato moral. Mesmo que o homem tenda a decidir conforme o que ele é, nenhum bem - exceto Deus, mas este não se apresenta em sua plenitude nesta vida - tem a força para determinar absolutamente o comportamento de alguém. Sob certo ponto de vista, cada coisa será tida como melhor em determinadas circunstâncias e pior em outras, com um número enorme de variantes a influenciar a decisão. As virtudes e os vícios indicam disposições para a decisão em um sentido ou em outro, mas não terminam de definir o que será decidido previamente; sempre cabe modificar o que seria de acordo com a tendência dominante no caráter daquele agente. Por isso, o ser humano não está fixado em uma determinada direção, mas inclinado, com maior ou menor força, conforme for mais ou menos arraig da sua virtude ou vício.

\section{E. Kierkegaard e a "escolha radical"}

Após essas considerações sobre a liberdade e suas motivações, podemos retornar a Kierkegaard. Para Stephen Evans, o pensador dinamarquês não propõe uma "escolha radical", no sentido exposto por MacIntyre de algo decidido sem razões prévias, a partir do qual fariam sentido as futuras escolhas do sujeito. Antes, para Kierkegaard, o agente teria motivos para suas ações, também para a primeira escolha fundamente da opção moral. Por isso, suas ações jamais 
seriam arbitrárias; tampouco seriam elas determinadas, porque as razões não determinam causalmente as ações (EVANS, 2006, p. 322-3).

Sustentar que Kierkegaard proponha uma decisão infundada seria um erro de perspectiva; na realidade, o autor considera que a liberdade é algo real, isto é, o agente é realmente uma "primeira causa" daquilo que realiza (KIERKEGAARD, 1962, p. 90-3). Em outras palavras, o sujeito detém a propriedade sobre as suas ações; ele, como alguém livre, é quem as leva a cabo. E a liberdade age em função de um interesse, de algo que o sujeito busca para si mesmo. Se não fosse assim, estaríamos no âmbito do "pensamento puro", que é duramente criticado pelo autor como algo inconsistente e falso (KIERKEGAARD, 2009a, p. 252-5). Admitir que decidimos movidos também por interesses, e não apenas por argumentos neutros ou puramente intelectuais, é algo que coloca Kierkegaard em sentido contrário a parte considerável da tradição iluminista anterior a ele, de modo especial Kant. Por outro lado, aproxima-o da concepção da tradição aristotélica, se estamos corretos ao sustentar que esta privilegia a decisão moral concreta, na qual influem inúmeros fatores - também os racionais, mas não exclusivamente -, como o interesse, a personalidade e as preferências do sujeito que vai agir.

Vale esclarecer que o interesse, no sentido em que Kierkegaard o considera, está bastante distante da acepção em que os utilitaristas o entendem. O interesse não é um prazer, uma vantagem, uma aquisição, compreendidas essas palavras em um sentido material ou sensual; antes, é o desejo de um bem, de algo que complementa, que torna pleno e aperfeiçoa.

Parece acertada a afirmação de Evans de que os argumentos apresentados pelo Juiz Guilherme (chamado também de "B" em Enten-Eller) para convencer o sedutor ("A"), de que a existência ética é superior à estética, são bons argumentos. Não podem ser aceitos apenas por quem primeiramente aderiu à concepção ética; antes, procuram que o destinatário pondere e reconheça que esta via traz vantagens e é mais perfeita do que a estética.

Assim, ainda que de forma velada, por trás das máscaras dos heterônimos, Kierkegaard estaria apresentando a sua posição. Ele o faz com arte, mostrando com força e honestidade a visão de mundo do homem estético; no entanto, já em Enten-Eller poderíamos discernir sua preferência pela vida ética.

Se de fato o Juiz Guilherme conseguiu ou não persuadir o sedutor, não dependeapenas da justeza e pertinência dos argumentos (EVANS, 2006, p. 3256). O ser humano pode se manter preso a uma determinada posição, por mais que ouça motivos fortes para alterá-la, porque sempre pode descobrir algo de 
bom nela. Esse algo de bom pode servir de bloqueio a qualquer possível vantagem moral que ele poderia obter ao deixá-la, passando a ser ético. Não se trata de que ele está decidindo contra a razão, ou faça o que não veja como melhor; naquela situação, permanecer na existência estética continua aos seus olhos o mais apropriado, na prática. Ele prefere os bens que obtém com o devaneio da imaginação e o afagos aos sentidos, que se desfrutam imediatamente, do que aquilo que poderia vir de uma vida regrada, que tem no casamento o seu modelo.

Para sermos justos com MacIntyre, ele reconhece que Kierkegaard não permaneceria para sempre um proponente da "escolha radical". Essa postura seria a esposa em Enten-Eller, que foi publicado em 1842; em escritos posteriores, no ano seguinte, ele já admitiria claramente razões que fundamentariam a decisão fundamental do agente (MACINTYRE, 2007, p. 41). Além disso, conforme examinaremos mais detalhadamente, Kierkegaard descobriria o modo de vida religioso, que seria aquele em que a busca de sentido do ser humano encontraria o seu término e sua justificação mais rotunda.

\section{F. A insuficiência do ético e o surgimento do religioso}

Em um escrito de 1843, Temor e tremor, Kierkegaard sustentará que o ético não é o estágio mais alto do ser humano. O homem ético vive de acordo com o universal, renuncia a si mesmo para poder expressá-lo. Surge então a figura do herói trágico, exemplificado em Antígona e em Sócrates, que se sacrificam em prol de uma concepção geral da lei, do que é correto. Porém, quem habita na esfera ética não considera o pecado, não o reconhece; antes, percebe a debilidade humana, mas julga que ela pode ser superada pela força de vontade e pela energia (COPLESTON, 1999, p. 267-8).

A consciência do pecado mostra que o ético não é suficiente. Há algo ao qual esse âmbito não chega. Ademais, o ético trata do ser humano como um universal, quando este deve ser principalmente um indivíduo, que entrará em contato com o Absoluto. O exemplo de vida religiosa, baseada na fé, seria Abraão, que creu contra toda esperança e viveu da fé, quando Deus pediu-lhe que sacrificasse Isaac, seu querido filho.

A respeito do patriarca judeu, pode-se dizer que há os que são grandes em virtude do seu poder; outros, por força da sua sabedoria; alguns, pela sua esperança ou pelo seu amor. Abraão, contudo, foi o maior de todos: grande com a 
sua força, cujo poder era a impotência; grande pela sua sabedoria, cujo segredo é a estultice; grande pela sua esperança, cuja forma é a loucura; grande pelo seu amor, que é ódio de si mesmo (KIERKEGAARD, 2013a, p. 207). Os parâmetros de bondade e de nobreza são distintos dos demais estágios, tanto quanto a fé supera a razão e a ética humanas.

De forma coerente, Kierkegaard afirma que ou o indivíduo pode permanecer como tal em uma relação absoluta com o Absoluto, e consequentemente o ético - que se mantém no universal - não é o mais alto, ou Abraão está perdido, porque ele não seria nem um herói trágico, nem um herói estético (KIERKEGAARD, 2013a, p. 335). Portanto, existe um terceiro estágio, com critérios diferentes dos anteriores e que os supera, que é justamente o estado religioso.

Haveria muitos aspectos a tratar sobre o estágio religioso em Kierkegaard. Tratase de uma noção que o autor manteve no decorrer de seus escritos posteriores, uma conquista intelectual da qual não abriu mão em nenhum momento. Aqui, gostaria de chamar atenção para outra similitude entre Kierkegaard e Aristóteles, sempre com o cuidado de não forçar exageradamente as semelhanças.

Aristóteles, em sua ética, afirma que a felicidade plena não é para todos os seres humanos. Apenas aqueles que podem levar uma vida de contemplação, para o que outros necessitam trabalhar para ele, e que jamais sofrem necessidades materiais importantes, nem lhes sucede nenhuma desgraça, voluntária ou não - a perda de um filho, uma deficiência física, a desonra por um fato aleatório, e assim por diante - poderia almejar uma felicidade verdadeira. Para a grande massa dos seres humanos, essa seria uma possibilidade fechada. Quanto mais pura a felicidade, menor o número de pessoas que dela poderiam desfrutar. Apesar de essa ser uma interpretação em muitos pontos sustentável, não nos parece a mais adequada. Antes de tudo, Kirkegaard é um cristão convicto. Por isso, brigou com a Igreja de seu país e da sua época, e quis sair do universal para chegar ao particular de um relacionamento individual com o Absoluto.

\section{Conclusão}

A respeito da existência de uma escolha radical, isto é, sem razões que a motivassem, no centro de Enten-Eller, a posição de Evans me parece em princípio mais consistente que a de MacIntyre. O que talvez tenha sucedido é que, na contramão de vários autores modernos, Kierkegaard havia desistido de propi- 
ciar uma fundamentação racional neutra e universal para a adoção de um modo de vida ético. Assim, seus argumentos - provavelmente sustentados pelo Juiz Guilherme - não têm a pretensão a algo definitivo, universal, matemático. De fato, dependem da boa disposição de quem os ouve (EVANS, 2004, p. 57-9).

No entanto, esse tipo de argumento é bastante similar ao proposto por Aristóteles e todos que seguiram a tradição inaugurada por ele, incluindo Tomás de Aquino. Não dependem de uma racionalidade científica, dedutiva, silogística, mas sim de uma dialética, perfectiva e, em certo sentido, precária. Essa racionalidade menos certa do que a científica foi marginalizada a partir de Descartes, que valoriza fundamentalmente a certeza; porém, ela é importante para compreender o pensamento antigo e medieval, aos quais, com todos os matizes, Kierkegaard aparentemente retorna.

Portanto, estaria correto considerar que Kierkegaard representa o primeirosintoma do fim, do esgotamento do projeto iluminista de justificação racional da moral, conforme defendido por MacIntyre. Porém, o pensador dinamarquês não se limitou a escapar de uma maneira de entender a ética que ele considerava insuficiente; ele propôs uma saída, em grande parte sustentada pela fé, compreendida em um primeiro momento de modo protestante, para progressivamente, conforme demonstram seus diários, se aproximar da visão católica da relação entre fé e obras e entre fé e razão (FABRO, 1967, p. 156-206). Este, no entanto, é um tema para outros estudos.

Seja como for, não é no âmbito ético que devemos buscar a última palavra a respeito de Kierkegaard. A fé de Abraão traz outra realidade, uma nova dimensão, que é muito mais completa e radical que a ética: a religiosa, pela qual a verdade se torna propriedade do agente, que adere a ela com a força de sua subjetividade.

Recebido em: 26/11/2015 Aprovado em: 12/02/2016

ABBÀ, G. Felicità, vita buona e virtù: saggio di filosofia morale. 2. ed. Roma: LAS, 1995.

ADAMS, Marilyn McCord. Ockham on will, nature, and morality. In: SPADE, Paul Vincent (ed.). The Cambridge Companion to Ockham. Cambridge: Cambridge University Press, 2006. p. 245-72.

ARISTOTLE. Nicomachean ethics. In: BARNES, J. The complete works of Aristotle: the revised Oxford translation. Princeton: Princeton University Press, 1991. t. 2.

COPLESTON, Frederick. Historia de la filosofia 7: de Fichte a Nietzsche. 4. ed. Barcelona: Ariel, 1999.

EVANS, C. Kierkegaard on faith and the self: collected essays. Waco: Baylor University Press, 2006.

.Kierkegaard's ethic of love: divine com- 
mandments and moral obligations. New York: Oxford University Press, 2004.

FABRO, C. Faith and reason in Kierkegaard's dialetics. In: JOHNSON, H. THULSTRUP, N. A Kierkegaard critique: an international selection of essays interpreting $\mathrm{Ki}$ erkegaard. New York: Harper \& Row, 1962. p. 156-206.

GARFF, J. Søren Kierkegaard: a biography. Tradução de Bruce H. Kirmmse. Princeton: Princeton University Press, 2005.

IRWIN, Terence. The development of Ethics: a historical and critical study. Oxford: Oxford University Press, 2009. v. 3: from Kant to Rawls.

KIERKEGAARD, S. Concluding unscientific postcript to the Philosophical Crumbs. Tradução de Alastair Hannay. Cambridge: Cambridge University Press, 2009a.

Enten-Eller: un frammento di vita. A cura di Alessandro Cortese. 4. ed. Milano: Adelphi, 1993. t. 1.

Enten-Eller: un frammento di vita. A cura di Alessandro Cortese. 3. ed. Milano: Adelphi, 2009b. t. 5. Fear and trembling. Repetitions. Tradução e edição de Howard V. Hong e Edna H. Hong. Princeton: Princeton University Press, 1983.

Le grandi opere filosofiche e teologiche. Testi originali a fronte. Tradução de Cornelio Fabro. Milano: Bompiani, 2013a.

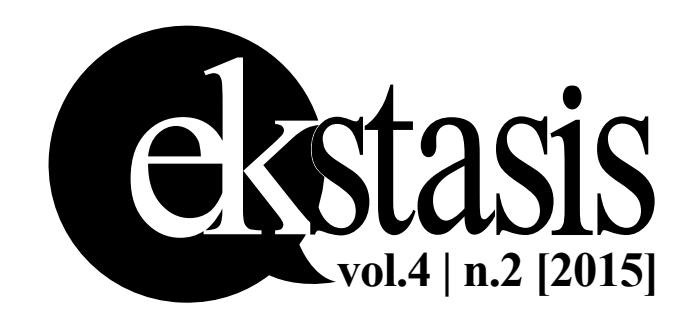

